\title{
Serviço Social e avaliações de negligência: debates no campo da ética profissional
}

\author{
Social Work and evaluations of negligence: \\ discussions in the field of professional ethics
}

Thais Peinado Berberian*

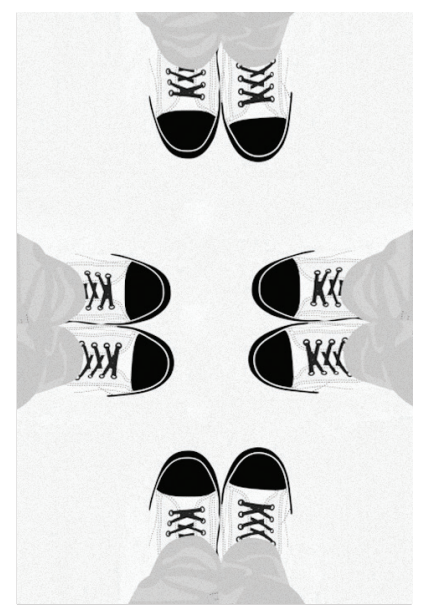

Resumo: As avaliações realizadas pelos assistentes sociais sobre situações de suspeita de negligência contra criança e adolescente compõem o cerne desta reflexão. A investigação sobre o uso, o próprio conceito utilizado e as implicações quando há a afirmativa de uma situação de negligência são debatidas neste artigo sob a luz da ética profissional.

Palavras-chave: Negligência. Serviço Social. Criança e adolescente. Ética profissional.

\begin{abstract}
Assessments carried out by social workers on cases of suspected neglect against children and adolescents reviews comprise the core of this reflection. Research on the use, the concept used and the implications when there is affirmative a situation of neglect are discussed in this article in the light of professional ethics.
\end{abstract}

Keywords: Neglect. Social Work. Children and adolescents. Professional ethics service.

* Mestre em Serviço Social na PUC-SP, Brasil. E-mail: thaisberberian@yahoo.com.br. 


\section{Serviço Social e o campo da infância e juventude}

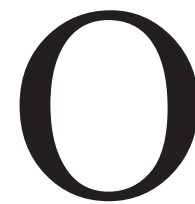

presente texto apresenta como objetivo central trazer para o debate algumas reflexões sobre o uso do conceito negligência pelo Serviço Social, especialmente nas intervenções com crianças e adolescentes. A investigação sobre o provável uso recorrente e viciado deste termo pela categoria profissional, com cunho moralista, para designar diversas situações de desproteção contra crianças e adolescentes se revelou como tema de estudo emergente e relevante, visto a incipiente produção do Serviço Social nesta temática. ${ }^{1}$

O Serviço Social apresenta significativa inserção de profissionais na área da infância e juventude. Constitui-se como uma das profissões de referência nesse setor e legitima-se historicamente para desenvolver suas atividades nessa temática na luta pela garantia de direitos.

O compromisso social com a defesa dos direitos da criança e do adolescente, que teoricamente deve ser compartilhado pela família, comunidade, sociedade em geral e pelo poder público, conforme prevê o Estatuto da Criança e do Adolescente (ECA), revela a concepção da infância como uma fase de fragilidade e, portanto, de necessário suporte e proteção ofertados pelos adultos.

A infância, tida como um dos segmentos sociais que ocupa a centralidade no debate contemporâneo em vista da luta pela garantia de direitos legalmente assegurados, é compreendida nesta reflexão como uma forma de ser socialmente construída, a partir das transformações societárias e das novas demandas surgidas do movimento da história.

A partir da observação empírica do cotidiano de trabalho do assistente social na esfera da infância e juventude, no que tange à demanda profissional para avaliação de suspeita de negligência contra criança e adolescente, observamos

1. Os apontamentos e reflexões aqui apresentados são frutos de dissertação de mestrado Serviço Social e avaliações de "negligência" contra criança e adolescente: debates no campo da ética profissional, defendida em outubro de 2013 no Programa de Estudos Pós-Graduados em Serviço Social da PUC-SP, sob orientação da profa. dra. Maria Lúcia Silva Barroco. Seu ponto de partida foi dado pelas inquietações oriundas da prática profissional, com a possibilidade de serem acolhidas e remetidas ao plano da reflexão crítica, por meio de um processo investigativo e sistemático, sob a luz do método marxiano. 
que um mesmo evento é capaz de mobilizar pareceres diferentes entre os membros da equipe, não permitindo deixar claro quais são os recursos e métodos utilizados pelos profissionais para a definição, em um atendimento, da negligência. Essa situação se revelou em nossa prática na medida em que apreendemos uma diversidade de condutas entre os profissionais acerca de ocorrências semelhantes envolvendo suspeitas de negligência.

Percebemos no trabalho profissional a repetição de uma prática que define diferentes eventos envolvendo os sujeitos a partir do conceito negligência, sem a radical problematização e reflexão do conteúdo desse conceito e da forma de seu uso. Essa observação do cotidiano profissional também possibilitou a identificação de que, por vezes, situações são entendidas como negligência sem qualquer recorrência à totalidade desses sujeitos, desconsiderando sua concreta inserção em uma sociedade que é real e se configura de maneira objetiva, com rebatimentos objetivos.

Famílias que vivem e convivem em condições-limite de vida e sobrevivência, muitas vezes perpassadas pelo uso/abuso de drogas, desemprego/subemprego, exposição às diversas manifestações de violência, fragilidade dos vínculos familiares, entre outros desdobramentos da questão social, frequentemente são questionadas pelos profissionais acerca da capacidade protetiva em relação a suas crianças e adolescentes, ocupando então um lugar de completa responsabilização pela oferta de cuidados e serviços a esses sujeitos, sem trazer para o debate a fundamental presença do Estado como provedor de um sistema de garantia de direitos.

Nesse contexto, passamos a observar um direcionamento profissional que tende a desvalorizar as condições reais existentes que interferem na capacidade dessas famílias de proteger suas crianças e, com isso, uma tendência a qualificar essas situações como situações de negligência, conforme problematizado por Fávero (2007, p. 161):

O poder saber profissional pode ter direcionamentos distintos, a depender da visão de mundo do profissional e de seu (des) compromisso ético. [...] A culpabilização pode traduzir-se, em alguns casos, em interpretações como negligência, abandono, violação de direitos, deixando submerso o conhecimento das determinações estruturais ou conjunturais, de cunho político e econômico, que 
condicionam a vivência na pobreza por parte de alguns sujeitos envolvidos com esses supostos atos.

Esse apontamento, aliado à nossa constatação, resultante da prática profissional, traz uma questão central para esta reflexão: na medida em que fatores tão concretos não estão sendo considerados no momento da intervenção profissional em avaliações de suspeita de negligência, quais outros elementos se fazem presentes para a fundamentação de determinada conduta profissional?

Diversas indagações também compõem o cenário de problematização dessa temática, sendo algumas delas: Quais são os critérios para definir que alguém é negligente? Eles são objetivos ou decorrem apenas de uma avaliação moral? Sendo uma atribuição negativa, contém um julgamento de valor; logo, não há como dizer que a moral não esteja presente. Além da moral, existem outros critérios objetivos? Quais são? A avaliação moral está pautada nos princípios do Código de Ética Profissional?

Diante de tantas indagações, uma observação relevante que norteou nossas aproximações ao tema é que, antes de tudo, trata-se de uma ação profissional que deve ser debatida no âmbito da ética profissional e do preconceito moral que pode estar inscrito no exercício da profissão. O termo preconceito aqui é conceituado como

uma forma de reprodução do conformismo que impede os indivíduos sociais de assumirem uma atitude crítica diante dos conflitos, assim como uma forma de discriminação, tendo em vista a não aceitação do que não se adequa aos padrões de comportamento estereotipados como "corretos" (Barroco, 2005, p. 47).

Vale ressaltar que a cotidianidade, entendida como o campo privilegiado de reprodução da alienação, dada as suas principais características como a heterogeneidade, repetição acrítica dos valores e a assimilação rígida dos preceitos e modos de comportamento, também abre espaço para o moralismo, movido por preconceitos:

Nos preconceitos morais, a moral é objeto de modo direto... Assim, por exemplo, a acusação de "imoralidade" costuma juntar-se aos preconceitos artísticos, 
científicos, nacionais etc. Nesses casos, a suspeita moral é o elo que mediatiza a racionalização do sentimento preconceituoso. (Heller, 2000, p. 56).

A partir dessas considerações iniciais, percebemos que as avaliações de negligência apresentam evidente relevância enquanto problema a ser investigado, reforçado pelo fato de se apresentarem no interior de uma incipiente discussão crítica e teórica na produção do Serviço Social, apesar de os assistentes sociais estarem diretamente relacionados a essas situações e inseridos nos espaços sócio-ocupacionais, onde são demandados a se posicionar diante de denúncias de negligência.

\subsection{Aproximações ao conceito negligência}

Para Guerra (1997, p. 45), a atenção voltada para a discussão da negligência ainda é menor quando comparada a outros tipos de violência, pois:

Os estudos a ela [negligência] relativos são de cunho mais recente porque enfrentaram dificuldades básicas de conceituação, uma vez que é preciso observar até que ponto um comportamento é negligente ou está profundamente associado à pobreza das condições de vida. Numa sociedade capitalista, onde a opressão econômica impera, as dificuldades de se abordar um fenômeno, que pode trazer à tona esta mesma opressão, estão presentes entre os pesquisadores.

Em investigação dos trabalhos publicados sobre o tema, a percepção de que o fenômeno da negligência não é recente e que se configura como uma das principais modalidades de violência contra crianças e adolescente foi recorrente. $\mathrm{O}$ entendimento de que se trata de um fenômeno complexo assim como a indicação de que a negligência não pode ser entendida apenas no contexto restrito das práticas internas das famílias, pois estas sofrem o impacto de fatores sociais, políticos, econômicos e jurídicos que criam dificuldades para prover os cuidados necessários aos filhos também se apresentou nos estudos investigados.

Outro apontamento relevante feito em trabalho publicado por Martins (2006) indica que em muitas situações o conceito negligência vem sendo usado 
como sinônimo para pobreza. Além dessas indicações, consideramos importante ressaltar que, por meio do processo investigativo, percebemos que o uso do conceito negligência também é partilhado por outras profissões, não sendo exclusivo do Serviço Social. No campo do Direito, encontramos referência à negligência no Código Penal (1940), quando realizada a diferenciação entre os crimes doloso e culposo, sendo este último resultado da ação de um agente por imprudência, negligência ou imperícia.

Segundo a ótica do Direito, compreende-se que existe negligência quando há desatenção ou falta de cuidado ao exercer certo ato, consistindo na ausência da necessária diligência. Diferentemente do dolo, que presume a ciência do dano (como objetivo ou possibilidade, em virtude do risco), a negligência, nessa perspectiva inicial, é a inobservância de normas que ordenam agir com atenção, capacidade e discernimento. Ainda na esfera do Direito, localizamos debate a respeito da intencionalidade da negligência compreendida como não apenas uma inobservância da lei, mas como uma ação incorporada por parcela de consciência e voluntarismo, em que a intenção é reconhecida e consciente (Código Civil, 2002).

Nos campos da Psicologia, Medicina e Enfermagem também encontramos referências à negligência, em maior escala localizadas nos códigos de ética profissionais. Ainda no campo da Psicologia e Enfermagem, podemos reforçar a identificação de produção científica no sentido de compreender e discutir a multidimensionalidade do fenômeno da negligência, especialmente em estudos que debatem situações envolvendo crianças e adolescentes.

Além dessas formas de abordagem do fenômeno negligência, em apenas alguns trabalhos foi localizada a preocupação com o uso do conceito negligência pelos profissionais da rede de serviços. Conforme aponta Mello (2008), constata-se na literatura uma falta de parâmetros homogêneos que identifiquem esse fenômeno, havendo a necessidade de se reconhecer os fatores que o constituem, em uma perspectiva multidimensional.

Em pertinente apontamento realizado por Fuziwara (2004), a autora indica preocupação diante dos múltiplos olhares técnicos que coexistem e subsidiam muitas decisões no campo sociojurídico (ressaltamos que essa preocupação não é exclusividade desse campo), sem que partilhem de uma explicitação norma- 
tizadora dos conceitos empregados pelos profissionais, sendo um desses o conceito de negligência.

Desta forma, o que podemos apreender a partir desse levantamento bibliográfico sobre o tema é a incipiente discussão sobre uma prática profissional recorrente na categoria profissional. Acreditamos que os rebatimentos dessa escassa apropriação são de ordens diversas, que, no entanto, trazem prejuízos especialmente aos sujeitos atendidos pelo Serviço Social, que invariavelmente podem ser atingidos por práticas alicerçadas em condutas preconceituosas e moralistas.

\subsection{0 que estamos chamando de negligência?}

A palavra negligência, originada do latim negligentia (desprezar, desconsiderar), segundo definição do dicionário Michaelis, significa falta de diligência; descuido, desleixo; incúria, preguiça; desatenção, menosprezo.

Utilizada em diversas áreas da divisão sociotécnica do trabalho, como Direito, Medicina, Psicologia e no Serviço Social (dentre outras), seu conceito carrega determinada definição e sentido social, mostrando-se funcional para embasar condutas ético-morais, justificar intervenções práticas e compor o repertório legal. Ao se revelar com circulação vasta por diversas áreas do conhecimento, sendo utilizado de forma corriqueira por diferentes profissões, o conceito negligência demonstra sua multiplicidade de sentidos e a necessária apropriação de seus significados em cada contexto.

Visto que em outras profissões o conceito negligência é em geral empregado para denominar situações em que o indivíduo está sendo avaliado negativamente em relação ao (não)cumprimento de alguma de suas responsabilidades, nos questionamos sobre os juízos negativos de valor já imbricados no uso desse conceito.

O que nos parece é ser a negligência um termo viciado de conteúdo moral, pois, ao mesmo tempo em que pode representar desatenção, também se mostra como sinônimo de desleixo e preguiça, por exemplo, trazendo inevitavelmente consigo conteúdos valorativos negativos, reforçando um perfil estereotipado e preconceituoso sobre o outro. 
Refletindo sobre o Serviço Social, entendemos que quando somos acionados para avaliar determinada situação em que há suspeita de negligência, precisamos avaliar o grau de desproteção em que se encontram as crianças e os adolescentes que vivem em determinado contexto. A desproteção em seu sentido objetivo, ou seja, como falta de proteção, que pode ser decorrência de uma situação intencional, ou não, dos responsáveis legais.

Reforçamos aqui a consideração da intencionalidade com o intuito de nos alinharmos ao entendimento de que pode haver situações de desproteção de crianças e adolescentes mesmo sem o consentimento ou a intenção dos responsáveis legais, conforme já ressaltado quando mencionamos as diversas situações de privação e violações de direitos vividas por muitas famílias que não detêm os recursos mínimos para suprir suas necessidades mais elementares.

A Constituição federal de 1988, assim como a Lei n. 8.080/1990, ao compreenderem o conceito saúde em sua forma mais ampliada, passam a reconhecer que as expressões da questão social são elementos significativos na composição do "status de saúde". Desta forma, o reconhecimento dos determinantes sociais, econômicos e culturais que interferem no processo saúde-doença revela-se essencial para a real apropriação das condições de saúde experimentadas pelos sujeitos atendidos pelos serviços.

Conforme afirmativa da lei, a saúde encontra como determinantes e condicionantes, entre outros, "a alimentação, a moradia, o saneamento básico, o meio ambiente, o trabalho, a renda, a educação, a atividade física, o transporte, o lazer e o acesso aos bens e serviços essenciais" (artigo 3º , Lei n. 8.080/1990).

A própria CID-10 (Classificação Internacional de Doenças) classifica entre os códigos Z55 a Z65 pessoas com riscos potenciais à saúde relacionados com circunstâncias socioeconômicas e psicossociais, apontando, entre outros fatores, os problemas relacionados com a educação e com a alfabetização (Z55), com o emprego e com o desemprego (Z56), com a habitação e com as condições econômicas (Z59), e ainda com o meio social (Z60).

Nessa perspectiva, conhecendo a realidade da maioria dos usuários dos serviços públicos de saúde, fazemos o seguinte questionamento: de que maneira o Serviço Social está realizando as avaliações de suspeita de negligência contra crianças e adolescentes diante de uma realidade tão fragilizada, em que 
as condições objetivas de vida interferem diretamente na qualidade da oferta de proteção e inclusive no grau de saúde das crianças e adolescentes?

\section{A pesquisa}

Diante dessas indagações e reflexões, foi realizada pesquisa qualitativa, ${ }^{2}$ com entrevistas individuais semiestruturadas com seis assistentes sociais escolhidos aleatoriamente, inscritos em diferentes espaços sócio-ocupacionais (Saúde, Assistência Social e Sociojurídico), que oferecem atendimento às famílias e que, entre outras demandas, atendem situações caracterizadas por negligência.

A partir de dezessete perguntas abertas feitas aos sujeitos, foi possível estabelecer com os mesmos a criação de um espaço de reflexão sobre esta demanda, que foi considerada recorrente no cotidiano de trabalho por todos os entrevistados.

Sobre 0 uso e o conceito negligência

Do universo dos entrevistados, percebemos que apesar de a maioria dos sujeitos indicar alguma referência teórica que subsidie a definição de negligência, os mesmos sujeitos demonstraram usar este termo para designar diversas outras situações de violência e até mesmo de pobreza. Notamos incipiente apropriação teórico-crítica por parte dos sujeitos entrevistados sobre esse conceito, que aparece de forma mecanicamente incorporada no discurso profissional.

Sobre o Serviço Social e 0 atendimento às situações de negligência

Identificamos que o lugar ocupado pelo Serviço Social, quando inserido em uma equipe multiprofissional, é de referência para o atendimento e estabelecimento de condutas em situações de negligência. Segundo a fala dos sujeitos,

2. Pesquisa aprovada pelo Comitê de Ética em Pesquisa PUC-SP. 
nota-se da equipe ainda uma expectativa de um profissional da coerção e do consenso, iluminada por problematização feita por Iamamoto (1992, p. 42; grifos da autora):

$\mathrm{Na}$ tentativa de explicar o que unifica a demanda do assistente social em programas multifacetados, pode-se levantar a seguinte hipótese, que direciona as reflexões que se seguem: o assistente social é solicitado não tanto pelo caráter propriamente "técnico-especializado" de suas ações, mas antes e basicamente pelas funções de cunho "educativo", "moralizador" e "disciplinador", que, mediante um suporte administrativo-burocrático, exerce sobre as classes trabalhadoras, ou, mais precisamente, sobre os segmentos destas que formam a "clientela" das instituições que desenvolvem "programas socioassistenciais". Radicalizando uma característica de todas as demais profissões, o assistente social aparece como o profissional da coerção e do consenso, cuja ação recai no campo político.

Sobre os critérios de identificação da negligência, poucos profissionais verbalizaram, em seus discursos, critérios claramente reconhecidos em sua prática profissional para a identificação da negligência.

Em relação aos encaminhamentos ao sistema de garantia de direitos, a fala dos profissionais evidenciou a fragilidade de muitos equipamentos públicos em oferecer os serviços esperados. Vale ressaltar que na fala de um profissional, a política pública da assistência social foi compreendida como ajuda, despolitizando o debate e reforçando o imaginário do assistente social como um profissional que oferece favores e apoio.

No entanto, cabe ressaltar que a maioria dos sujeitos se posicionou de forma crítica sobre o fazer profissional, identificando os limites e as contradições impostas pela própria realidade, com rebatimentos diretos na ação profissional.

Sobre a interface com a ética profissional e valores

Por compreendermos de maneira ontológica a inscrição dos valores nas ações práticas dos assistentes sociais, a discussão no campo da ética profissional ganhou espaço relevante nessa pesquisa, na medida em que buscamos identificar 
a inscrição de valores negativos nas avaliações de suspeita de negligência contra crianças e adolescentes.

A família recebeu evidência nessa análise, por continuar sendo, de maneira histórica, o objeto central de intervenção do assistente social, com apoio cada vez maior das diretrizes de políticas públicas no âmbito da seguridade social.

Conforme aponta Mioto (2012, p. 125), é necessário atentarmos para os “discursos e práticas de responsabilização das famílias altamente naturalizadas no processo de execução das diferentes políticas sociais, e nos quais os assistentes sociais estão profundamente envolvidos", em que, segundo nossa percepção, é possível localizar a transferência de responsabilidades do Estado para a figura da família, assim como sua culpabilização pelo não desempenho das funções a ela atribuídas.

Durante as entrevistas com os sujeitos, foi possível apreender que os elementos da cotidianidade marcam de maneira significativa a prática e o discurso profissional, e quando não realizado o movimento de suspenção da realidade, a possibilidade de práticas preconceituosas e acríticas mostram-se evidentes. Segundo Barroco (2010, p. 72):

Em função de sua repetição acrítica dos valores, de sua assimilação dos preceitos e modos de comportamento, de seu pensamento, repetitivo e ultrageneralizador, a vida cotidiana se presta à alienação. A alienação moral também se expressa através do moralismo, modo de ser movido por preconceitos. Devido ao seu peculiar pragmatismo e sua ultrageneralização, o pensamento cotidiano é facilmente tentado a se fundamentar em juízos provisórios, ou seja, em juízos pautados em estereótipos, na opinião, na unidade imediata entre o pensamento e a ação.

A partir dos discursos dos sujeitos, esses estereótipos apareceram em nossas entrevistas como referência às famílias atendidas, sendo alguns deles: suja, maltrapilha, destratado, ignorante, despreparado, ruim, incapaz, sem noção de nada, respondona.

Todas essas referências estavam relacionadas aos juízos de valor atribuídos por alguns de nossos sujeitos, assistentes sociais, às famílias atendidas, e revelam, na medida de sua utilização, um importante direcionamento profissional 
calcado em desvalor. Além de uma atribuição valorativa negativa, há um moralismo, já que tais atribuições são movidas por preconceito, aqui compreendido como uma forma de alienação moral.

É interessante problematizar essa prática profissional, pois na medida em que as situações de negligência são avaliadas a partir de critérios morais, em que há quesitos preestabelecidos sobre o "bom", "adequado", "capaz", "normal”, elas passam, com grande chance, a ser discriminadas e (des)valorizadas moralmente. Desta forma, a questão é que, para essas avaliações, se faz necessária a utilização de outros instrumentos avaliativos que não pertençam à esfera da moralidade, já que o objeto dessa avaliação não deveria ser avaliado do ponto de vista moral.

Ainda assim, é importante reforçar que não estamos aqui negando a apropriação, fruto de uma elaboração histórica e coletiva, do que socialmente é compreendido pelo conjunto de cuidados necessários para o desenvolvimento saudável e integral de crianças e adolescentes, e que deve, de alguma forma, nortear as avaliações de situações de negligência. Queremos ressaltar que esse "padrão de cuidados", também imbuído de valores, deve ser questionado e considerado a partir da apreensão de todas as mediações contidas nessas situações, para que as avaliações, que precisam ser técnicas, não recaiam no moralismo.

Toda avaliação que atribua ao outro determinados juízos implicará consequências e rebatimentos àqueles que estão sendo avaliados, sendo, portanto, uma atitude inscrita na esfera da ética, já que exige do profissional o reconhecimento de que suas ações terão implicações para o outro.

Por mais que tais avaliações exijam do profissional determinado grau de consciência, nem sempre esta se materializa no cotidiano profissional, fazendo com que muitas intervenções, motivadas pela imediaticidade e espontaneidade, ocorram sem acessar o nível da consciência. Não acessar a consciência não significa eximir a responsabilidade profissional, pois independentemente do grau de incorporação crítica do profissional, suas ações, inevitavelmente, terão rebatimentos nos sujeitos. Conforme aponta Barroco (2012, p. 32),

as ações cotidianas dos assistentes sociais produzem um resultado concreto que afeta a vida dos usuários e interfere potencialmente na sociedade e que nessas 
ações se inscrevem valores e finalidades de caráter ético. É verdade que essa interferência ocorre independente da consciência individual dos profissionais.

Assim, apreende-se que, independentemente do grau de apropriação crítica do profissional, os rebatimentos de suas condutas ocorrerão de maneira objetiva, na vida daqueles que estão sendo atendidos pelo assistente social. Portanto, temos um importante elemento para a discussão: o compromisso ético-profissional. Responsabilizar-se por suas ações, mensurar as suas consequências, eleger valores norteadores de acordo com o projeto ético-político da profissão e procurar efetivá-los nas ações profissionais são comportamentos esperados de uma ação ética, os quais, para ocorrer, precisam estar incorporados de forma consciente pelos profissionais.

Esta incorporação consciente mostrou-se ausente por parte de alguns sujeitos, especialmente quando questionados sobre a inscrição de valores em suas práticas profissionais. Para a metade dos sujeitos entrevistados, a prática profissional é neutra, parcial, sem qualquer interferência de valores. Para esses sujeitos, há uma compreensão de neutralidade e parcialidade do exercício profissional, em que é possível concretizar ações sem a presença de valores.

Resgatando o pressuposto da neutralidade, que como é sabido teve forte influência na trajetória profissional, especialmente nos Códigos de Ética anteriores ao de 1986, com expressiva interferência do Positivismo, percebe-se que a compreensão e a idealização de uma prática "neutra" ainda persistem no imaginário profissional.

Esses exemplos trazidos pelos profissionais reforçam nossa afirmação inicial sobre a inscrição de valores nas práticas profissionais, assim como apontam para a existência de condutas profissionais ainda atreladas àqueles valores relacionados ao preconceito e à discriminação. Observa-se que para aqueles profissionais que apontaram valores inscritos nas ações profissionais, tanto o exercício profissional em sua totalidade quanto o atendimento específico às situações de negligência apareceram de forma mais problematizada, mediada e crítica, se comparada aos sujeitos que apontaram para uma suposta neutralidade das ações.

Apontamos que foi possível identificar maior coerência no discurso profissional daqueles sujeitos que conseguiram apreender a presença de julgamentos de valor, e até mesmo de certo moralismo na prática profissional, bem como 
nas avaliações de suspeita de negligência. Afirmamos isso, pois para a maioria daqueles sujeitos que refutaram a presença de valores na prática profissional, percebemos justamente o contrário, uma prática muito influenciada por valores ainda conservadores, de cunho até mesmo autoritário, no que se refere à relação com o sujeito atendido.

Ou seja, para aqueles sujeitos que compreenderam haver a inscrição de valores no exercício profissional, e, além disso, que apontaram para a existência de juízos de valor (positivos ou negativos), a postura profissional é diferenciada em relação aos sujeitos que não reconheceram essa situação. Diferenciada no sentido de se atrelar a uma postura mais questionadora acerca do papel protetivo do Estado, das funções e atribuições assumidas pela própria profissão, nessas avaliações, assim como um discurso mais crítico e incomodado com a realidade vivida pelos sujeitos atendidos.

$\mathrm{O}$ fato de a ética não ter sido alvo direto do discurso da maioria dos sujeitos, quando questionados sobre a possível presença de juízo de valor no atendimento profissional das situações de negligência, nos faz refletir sobre qual espaço, na atualidade, a esfera da ética ocupa e dialoga no cotidiano profissional. Tendemos a acreditar que a esfera da ética ainda está intimamente relacionada a acontecimentos nitidamente caracterizados como antiéticos. Ou seja, em situações do cotidiano em que os profissionais não estabeleceram as mediações necessárias para compreender a implicação ontológica da ética, essa esfera parece passar despercebida, com menos relevância, apartada conscientemente das ações profissionais.

Assim, trazer para o debate a atitude ética não apenas para a concretização das avaliações de situações de negligência, mas para o espaço cotidiano do assistente social, parece-nos importante imperativo, a fim de contribuir para a desmistificação desse campo, que é insuprimível da prática profissional.

\section{Algumas considerações}

Da perspectiva da utilização do conceito negligência pelos assistentes sociais entrevistados, ficou evidente a incipiente apropriação crítica do uso do conceito negligência. Apesar de conceitualmente definirem de maneira ainda 
introdutória o que compreendem por negligência, os sujeitos demonstraram, na prática profissional, que esse conceito é utilizado de forma ampla para caracterizar diversas outras situações.

Entendemos que a escassa produção acadêmica sobre o tema no campo do Serviço Social, a tendência observada em relação à errônea correlação imediata entre as situações de pobreza vividas pelas famílias e a caracterização da negligência, assim como a incorporação acrítica e imediata desse conceito por grande parcela dos profissionais sejam alguns dos indicadores que auxiliem a compreensão de uma forma precipitada de utilização do conceito negligência na prática profissional.

As características que moldam o cotidiano também se revelaram como importantes componentes que interferem de forma imediata no modo com que os assistentes sociais estabelecem suas relações com os demais profissionais, com os sujeitos atendidos, bem como estabelecem a sua rotina de trabalho. A repetição, a fragmentação, o imediatismo e o pragmatismo, elementos da vida cotidiana, se desvelaram como indicadores de relevância na compreensão do uso do conceito negligência pelos assistentes sociais, uma vez que a vida cotidiana se mostra como o espaço da reprodução do trabalho do assistente social.

Diante dessas considerações, ratificamos a sugestão de utilização, por parte do Serviço Social, do termo desproteção em substituição a negligência, uma vez apontados os inúmeros comprometimentos do emprego desse último conceito. Percebemos, ao longo dos estudos, que o conceito negligência por si já tem em seu conteúdo um teor valorativo negativo, e que, de antemão, ao ser utilizado largamente sem a perspectiva crítica, indica de alguma maneira um juízo de valor preconcebido que tende a discriminar o sujeito.

Entendendo que para as demandas de "situações de negligência" a intervenção do assistente social deva ser direcionada para a identificação de possíveis violações de direitos, avaliamos que o termo desproteção atinja seu intento de forma satisfatória. Isto porque esse termo não se baseia em nenhum pré-julgamento em relação ao agente, ou seja, não discute o seu perfil moral, e sim as condições reais que interferiram para determinada situação.

Todas as manifestações capturadas ao longo das entrevistas que permitiram identificar expressões de preconceito relacionadas às famílias atendidas e 
definidas como negligentes serviram de elementos para a reflexão sobre o modo com que muitas avaliações profissionais têm se dado no exercício profissional. Um modo norteado por juízos de valor não alinhados aos valores defendidos pelo Código de Ética Profissional do Assistente Social, que conforme visto, muito embora hegemônico, não se concretiza de forma absoluta no dia a dia do assistente social, dado o movimento contraditório e dialético da realidade.

$\mathrm{O}$ fato de metade dos participantes da amostra compreenderem que não há a interferência de juízos de valor, quando requisitados a se posicionar diante de uma suspeita de situação de negligência, é suficiente para ratificar a pungente necessidade de trazer ao debate profissional a permanente discussão sobre valor, ética e moral. A não identificação do emprego de julgamentos morais nas avaliações de negligência, conforme já explicitado anteriormente, não significa a sua inexistência. Em outras palavras, o não reconhecimento dessa ação não anula a sua realização, assim como não impede nenhum rebatimento e consequência aos envolvidos.

Da mesma forma, o fato da outra metade dos participantes da amostra conseguirem apreender a existência de valores implicados nas avaliações de negligência e problematizar aquelas situações entendidas por ela como emblemáticas no que se refere ao conflito de valores, estando esses situados em campos mais conservadores ou mais emancipatórios, também revelou perspectiva importante a ser destacada: a de cunho crítico.

Validamos como consideração a existência de um campo de embate e disputa, mesmo que inconsciente, de práticas profissionais com maior ou menor possibilidade de concretizar valores de ordem emancipatória. Se as nossas inquietações iniciais se situavam sobre quais eram os critérios para compreender que alguém é negligente; se eram objetivos ou decorriam apenas de uma avaliação moral; e ainda se a avaliação moral estava pautada nos princípios do Código de Ética, tivemos muitas das respostas trazidas pelos depoimentos dos sujeitos, discutidos na análise.

E a partir dessa análise, tendo reconhecida a prática profissional com objetivação de valores negativos, o que consideramos importante apresentar como desafio é a necessária aproximação, por parte dos profissionais, dos debates que tratem sobre a ética no sentido de ampliar o grau de consciência, possibilitando ações cada vez mais conscientes e dirigidas para o projeto profissional e socie- 
tário construído hegemonicamente pelo coletivo da profissão, conforme afirma a história do atual Código de Ética. Afirmamos essa necessidade tendo em vista ainda o parcial entendimento que parte da categoria tem sobre a dimensão ética, tratando-a como algo abstrato, apartado do cotidiano profissional.

Outro desafio que localizamos especialmente relacionado às situações de negligência, mas que se inscreve na totalidade da prática profissional, é a necessidade de superação de práticas que estejam situadas no senso comum. Os exemplos aqui oferecidos foram ricos no sentido de traduzir as inúmeras possibilidades profissionais existentes frente às avaliações de suspeita de negligência, exigindo do profissional capacidades múltiplas para a apreensão das mediações postas.

Sendo assim, a formação continuada, o compromisso ético-político para a realização de atendimentos comprometidos com a população, a construção permanente de espaços institucionais que possam contribuir para o diálogo e o crescimento intelectual dos profissionais, assim como a defesa de relações de trabalho horizontais nas equipes multiprofissionais, a fim de não hierarquizar o saber, se mostram como imperativos para uma prática profissional coerente com suas finalidades, dispostas em nosso Código de Ética.

Recebido em 9/5/2014 - Aprovado em 24/11/2014

\section{Referências bibliográficas}

BARROCO, Maria Lúcia Silva. Ética e Serviço Social: fundamentos ontológicos. 3. ed. São Paulo: Cortez, 2005.

. Ética: fundamentos sócio-históricos. 3. ed. São Paulo: Cortez, 2010. (Coleção Biblioteca Básica para o Serviço Social, v. 4.)

;TERRA, Sílvia Helena. Código de Ética do/a assistente social comentado. São Paulo: Cortez, 2012.

BERBERIAN, T. P. Serviço Social e avaliações de "negligência" contra criança e adolescente: debates no campo da ética profissional. Dissertação (Mestrado em Serviço Social) - Pontifícia Universidade Católica, São Paulo, 2013. 
BRASIL. Decreto-lei n. 2.848, de 7 de dezembro de 1940. Código penal. Rio de Janeiro, 1940 .

BRASIL. Constituição da República Federativa do Brasil. Brasília, Senado, 1988. . Lei federal n. 8.069, de 13 de julho de 1990. Estatuto da criança e do adolescente. Brasília, 1990.

. Decreto-lei n. 8.080, de 19 de setembro de 1990. Brasília, 1990.

. Decreto-lei n. 10.406, de 10 de janeiro de 2002. Código civil. Brasília, 2002.

CONSELHO FEDERAL DE SERVIÇO SOCIAL (CFESS). Código de ética do assistente social. Brasília: CFESS, 1993.

FÁVERO, Eunice Teresinha. Questão social e perda do poder familiar. São Paulo: Veras, 2007.

FUZIWARA, Áurea Satomi. Significados em disputa: reflexão sobre a influência dos laudos técnicos dos assistentes sociais do Judiciário paulista e das representações sociais na jurisprudências que tratam de "negligência" no cuidado de crianças e adolescentes. In: CBAS 11., Brasília, 2004.

GUERRA, Viviane Nogueira de Azevedo. Apostila telecurso de especialização na área da infância e violência doméstica: $1 \mathrm{a} / \mathrm{b}$ pondo os pingos nos is. Guia prático para compreender o fenômeno. São Paulo: Iacri/Ipusp/USP, 1997.

HELLER, Agnes. O cotidiano e a história. 6. ed. Rio de Janeiro: Paz e Terra, 2000.

IAMAMOTO, Marilda Vilela. Renovação e conservadorismo no Serviço Social: ensaios críticos. São Paulo: Cortez, 1992.

MARTINS, Fernanda Flaviana de Souza. Crianças negligenciadas: a face (in-)visível da violência familiar. Dissertação (Mestrado em Psicologia) — Pontifícia Universidade Católica de Minas Gerais, Belo Horizonte, 2006.

MELLO, Ida Leyda Martinez Ávila. Negligência: contribuições para a avaliação de fatores de risco psicossociais em famílias assinaladas junto ao Conselho Tutelar. Dissertação (Mestrado) - Faculdade de Filosofia, Ciências e Letras de Ribeirão Preto, Universidade de São Paulo, Ribeirão Preto, 2008.

MIOTO, Regina Célia Tamaso. Processo de responsabilização das famílias no contexto dos serviços públicos: notas introdutórias. In: SARMENTO, H. B. M. (Org.). Serviço Social: questões contemporâneas. Florianópolis: Ed. da UFSC, 2012. 